\title{
Experience of Planning the Local Climate Change Adaptation Plan in Taoyuan
}

\author{
Hung-Pin Huang ${ }^{1}$ and Tih-Ju Chu ${ }^{2}$ \\ 1. Department of Bioenvironmental Systems Engineering, National Taiwan University, Taipei 10617, Taiwan, R.O.C. \\ 2. Department of Public Works, New Taipei City Government, New Taipei City 22001, Taiwan, R.O.C.
}

\begin{abstract}
Based on the experience of emergency operation on earthquake and flooding in local and foreign countries, the secondary disasters of fire, damage of critical infrastructure usually harmed lives or disturbed living condition. In order to safeguard people's lives and property safety, Taoyuan City Government, except for elementary public facilities, added standardized disaster prevention parks and detention ponds in the zone-expropriation project at Chunglu area. The zone-expropriation project at Chunglu, Taoyuan is designed for 487,600 residents in 2021. The area of public facilities of park, school, road and green land is 50.7 ha, $41.88 \%$ of total development area of 122.06 ha, in which, the capacity of disaster prevention parks at Chunglu area is designed for 3,164 refugee in 7.54 ha. An underground storage construction, withstand 7-magnitude earthquake, could supply the amount of water consumption of 3 $\mathrm{L}$ daily per person, lasting at least four weeks. The capacity of two detention ponds is $87,800 \mathrm{~m}^{3}$. During normal times, the disaster prevention park and detention ponds can be used as a recreational space for residents. When a disaster occurs, shelters are set up in the parks to accommodate residents to protect lives and property. And, detention ponds could adjust outflow discharge into neighborhood drainage system to mitigate disaster happening. Because the construction of standardized disaster prevention park with climate change needs much more land area, the acquisition of private land area is very difficult either general acquisition or zone expropriation in urban area. During each stage of zone expropriation, the support of landlord and Mayor Wu is very important. By means of public participation, information meeting was held hundreds times and revised content according to landlord's positive opinion. Moreover, the design idea and content was discussed with consultant-company mutually from time to time. Fortunately, this project is finished successfully and got award from Public Construction Council of Taiwan in 2014.
\end{abstract}

Key words: Taoyuan, Chunglu, detention pond, disaster prevention park, climate change.

\section{Introduction}

Taoyuan City is located southwest of Taipei in northern Taiwan and occupies $1,220 \mathrm{~km}^{2}$. It is made up of plain, hillside and tableland. By the end of 2014, the population is about 2.06 million. Because most of people live in plain area, the population density in urban area is particularly higher than rural area. The average temperature is 22.5 degrees of Celsius and relative humidity of 79\% with 101 rainy days in 2014. For the past few years, the nature disasters occurred frequently in Taiwan, such as "921" earthquake, typhoons “Aere” and "Morakot”. All these disasters caused a great deal of casualty and property lost. Taoyuan City had also suffered different ranks of lost

Corresponding author: Hung-Pin Huang, Ph.D., professor, research field: hydraulic engineering. during these disasters.

According to these experiences, Taoyuan City Government not only prepared strategies for disaster relief but also learned the concept of planning and building the disaster prevention park from Japan. The main purpose of this concept is to choose a place which is widely enough to have an open space to be used for a disaster prevention park and detention pond. The disaster prevention park and detention pond can be used for daily recreation, leisure and exercising function and, during the major disaster, a useful and important place for disaster shelter and flooding mitigation, respectively. Hence, we can ensure the safety of people's life and reduce the properties damage. 


\section{Effect of Climate Change in Taoyuan}

Based on the investigation data of 1980 1999, the simulation Scenario A1B explores that river discharge will increase in wet season (May October) and decrease in dry season in Taiwan from 2020 to 2039. That is, the impaction of local climate change in Taoyuan will be increasing temperature, rainfall intensity, soil erosion, extreme rainfall events, drought and decreasing agricultural product. In order to mitigate these impact in the future, Taoyuan City Government made a policy decision at the beginning of 2012. The principle idea is that each urban plan has a responsibility to absorb increased runoff from its development and operation [1]. And, green, ecology, resilience and sustainability will be the core value of urban plan.

\section{Plan and Design of Multi-function Parks in Taoyuan City}

\subsection{Zone-Expropriation Project at Chunglu}

At the same time, the public works of zone expropriation of Chunglu in Taoyuan District is about to begin so that this zone-expropriation plan is naturally considered as a first example of new policy. First of all, associated with the zone expropriation of Chunglu [2], the high-quality landscape of park is designed functions of low impact development, recreation, LOHAS (lifestyles of health and sustainability), as well as disaster prevention. Hence, larger area of green land, enough detention capacity and function of disaster prevention would be the major items of public works of this new development zone. The development area of Chunglu (Fig. 1) is 122.06 ha, where the area of public works is 50.7 ha, $41.88 \%$ of total area, in which the area of park, children's playground, green land, greenway, parking lot, school site, ditch and channel is 32.05 ha, $26.25 \%$ of total area. This large proportion of green land is not only larger than required area but provides big amount of rainwater storage capacity. Deducting the river and dense residential areas, as well as public works, road land, industrial zone which has been expropriated before, the area of zone expropriation of Chunglu is 105.69 ha.

Because most of urban area are private property, the ownership of land for public facilities of road, park or school, etc. is always acquired by either general acquisition or zone expropriation. The general acquisition needs the target of public benefit and prepares much money to buy landlord's ownership.

Except for the same requirement of public benefit, zone expropriation let landlord to get the same value of land area in the same development project. For fairness and feasibility, local government prefers using zone expropriation, recently.

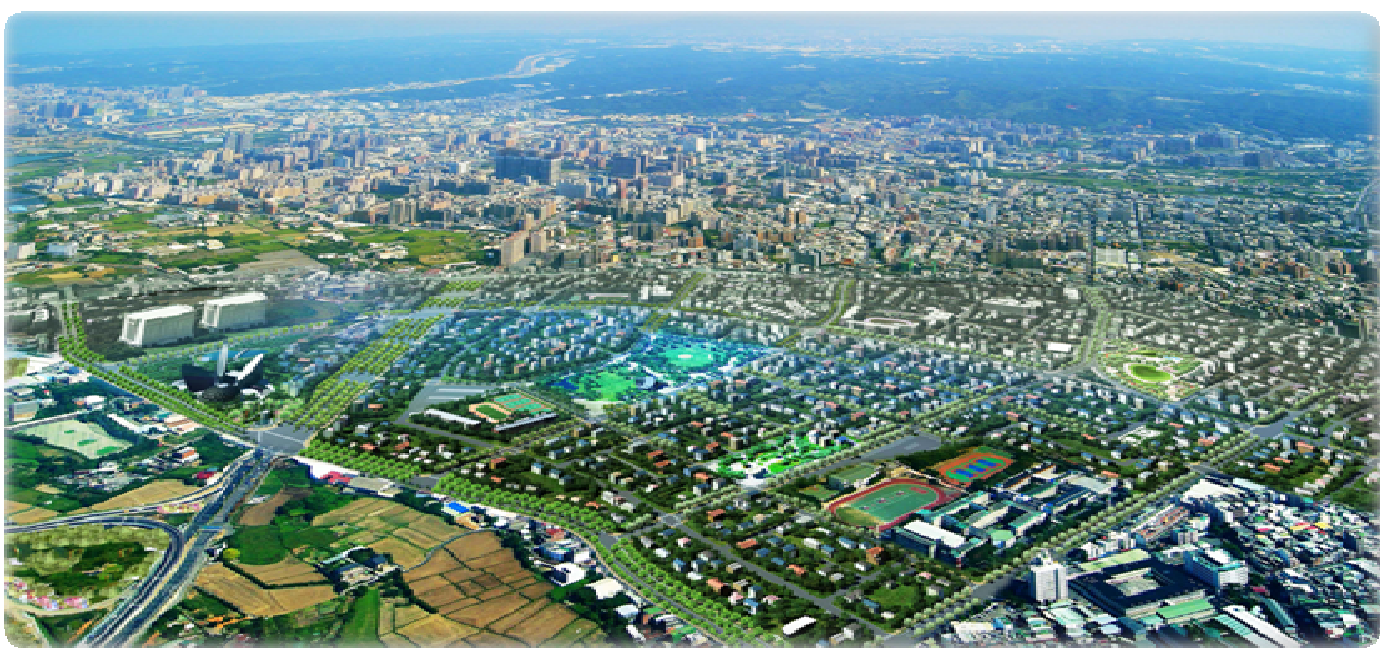

Fig. 1 Aerial view of Chunglu development area. 


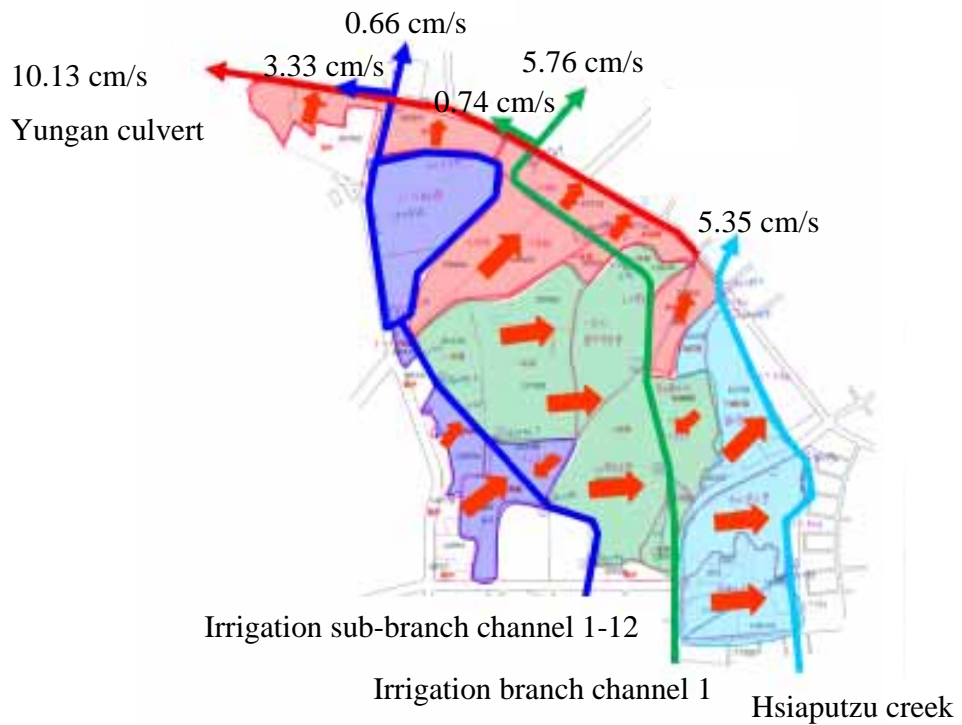

Fig. 2 The drainage system of Chunglu development area.

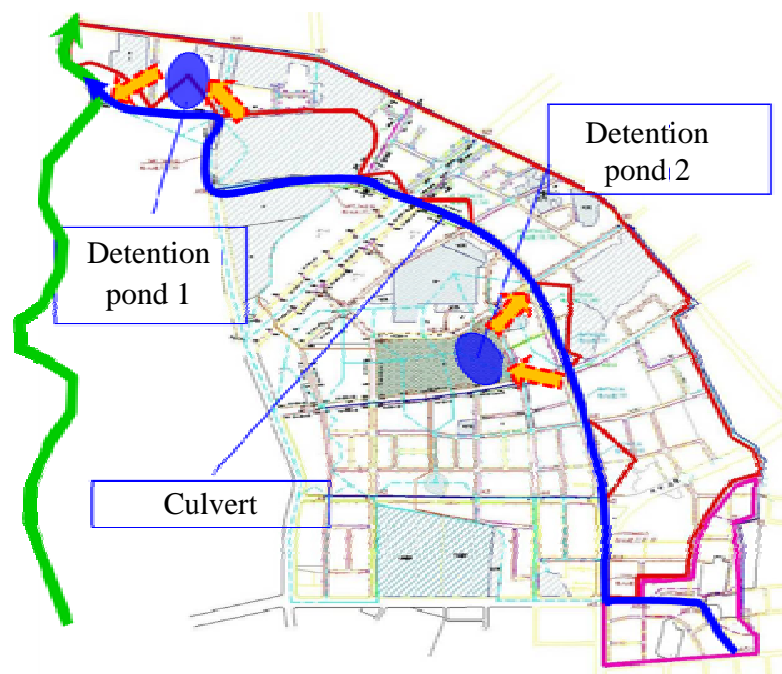

Fig. 3 Series of detention ponds in Chunglu development area.

Up to now, most of urban plan in Taiwan has no any consideration with climate change. And, during this decade, strong rainfall event and great earthquake happened frequently in Taiwan. Hence, in order to safeguard residents in Taoyuan, the disaster parks and detention ponds are firstly designed in this zone-expropriation project.

\subsection{Drainage System}

The drainage system of Chunglu area (Fig. 2) is the part of the watershed of Chiehtung creek [3]. Chiehtung creek is the tributary of Nankan creek and its watershed area is $61.05 \mathrm{~km}^{2}$ with creek length of $15.1 \mathrm{~km}$. The area of interior drainage system of Chunglu urban-planning is 700 ha; whereas outer area is 4,000 ha. And, there are three types of drainage systems in development area. That is, areal drainage system including Chiehtung and Hsiaputzu creeks, farmland irrigation system and rainwater sewer including culvert under Yungan and Kuochi roads. And, 
the increased runoff of Hsiaputzu creek will be $0.89 \mathrm{~m}^{3} / \mathrm{s}$ because the runoff after development is $6.24 \mathrm{~m} \mathrm{~m}^{3} / \mathrm{s}$ whereas $5.35 \mathrm{~m}^{3} / \mathrm{s}$ before development. Hence, the interception culvert of $1.5 \mathrm{~m}^{3} / \mathrm{s}$ will be located at upstream end to separate the amount of runoff. For farmland irrigation system, the sluice gate and side channel will be set up at the upstream end of development area to control the inflow discharge from farmland irrigation channel.

\subsection{Detention Ponds}

Refs. [4, 5] showed the importance of urban disaster prevention park. The series of two detention ponds (Fig. 3) will be located at the central and downstream section of development area to provide detention duration of one hour and detention capacity of $57,800 \mathrm{~m}^{3}$ and $30,000 \mathrm{~m}^{3}$, respectively. The reoccurrence interval of detention pond is designed as 10 years [6]. And, the demand detention capacity is $19,200 \mathrm{~m}^{3}$ with outflow of $1.18 \mathrm{~m}^{3} / \mathrm{s}$ at Central Urban Park, and 24,142 $\mathrm{m}^{3}$ with $3.03 \mathrm{~m}^{3} / \mathrm{s}$ at school site, in which, the area of detention pond in Central Urban Park is 12,691 $\mathrm{m}^{2}$ and the other one is $8,000 \mathrm{~m}^{2}$. And, they are $28 \%$ of Central Urban Park (4.6 ha) and 32\% of school site (2.5 ha). For the setup of detention ponds, the culvert discharge under Yungan road will be decreased to $8.04 \mathrm{~m}^{3} / \mathrm{s}$ from $10.13 \mathrm{~m}^{3} / \mathrm{s}$. Moreover, the reoccurrence interval of drainage system in development area is designed as five years. All of this consideration is to make sure the development area could mitigate the potential flood disaster and absorb its increasing runoff. Especially, the outflow of main culvert of development area to Chiehtung creek that has not regulated yet, will be controlled under $3.5 \mathrm{~m}^{3} / \mathrm{s}$. Both of these two detention ponds can be used for daily recreation, leisure site and be used for flood mitigation during flooding days.

\subsection{Disaster Prevention Work}

Taoyuan City Government chose Chunglu area to design and build a 3,164-refugee capacity of disaster prevention parks and the total area covered with
7.54 ha. An underground storage construction (Fig. 4), withstand 7-magnitude earthquake, could supply the amount of water consumption of $3 \mathrm{~L}$ daily per person, lasting at least four weeks. The disaster prevention parks (Fig. 5) includes in three sites of Central Urban Park (Fig. 6) of 4.6 ha, Urban Scenery Exercising Park (Fig. 7) of 2.16 ha and Neighborhood Art Park (Fig. 8) of $0.78 \mathrm{ha}$, respectively. The whole idea is to integrate waterway scenery, park road combination, exercising park, flood mitigation and disaster prevention function all to gather. The construction principle for those parks was mainly focused on the green environment framework, water resource management, low impact development and microclimate adjustment to achieve the goal of mitigating environmental impact from zone-expropriation project.

In average, a refugee needs at least $2 \mathrm{~m}^{2}$ in the park and all the required living materials, resource and facilities should be allocated accordingly. The disaster prevention park is a place for taking refuge or rescue support. The local government should instantaneously supply enough foods, water, electricity and communications for a short period of time when a disaster happens.

\subsection{Green, Ecology, Resilience and Sustainability}

Generally, Taoyuan City has a characteristic of insufficient water resource so that 2,851 farm ponds have made by ancestors from Ching Dynasty. Hence, how to increase green area and decrease impermeable area except for function of flood mitigation and disaster prevention would be the major works in Chunglu development area. That is, rainfall storage, grass ditch, ecological pond and green building are built and spread in green lands to achieve the target of maximum infiltration and storage as well as minimum surface runoff. Measures of $30-\mathrm{cm}$ topsoil conservation, lightweight construction, existed tree preservation and conservation, wood and pebble reuse, wheelchair accessibility are required during construction and operation periods. And, the solar panels device located 


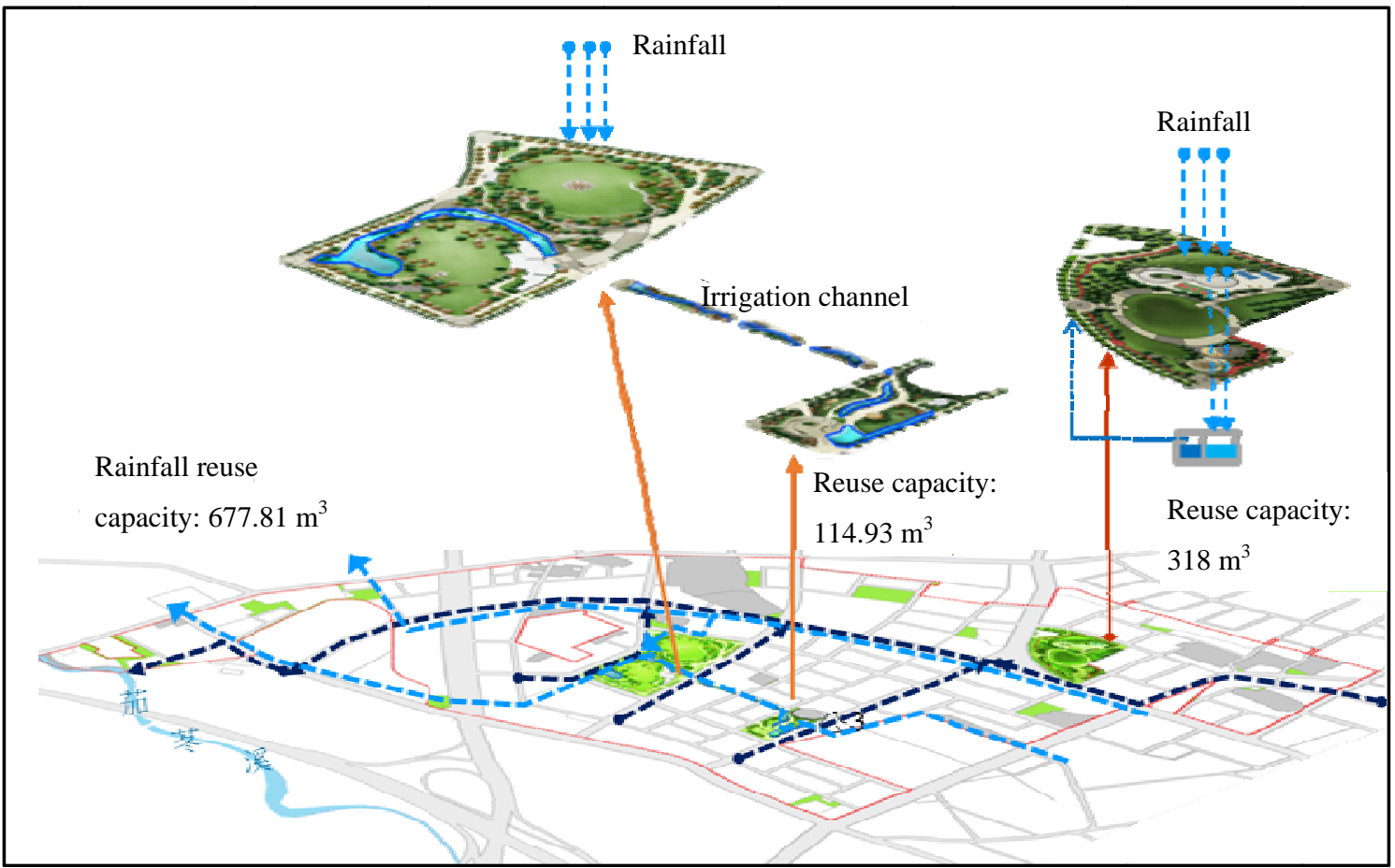

Fig. 4 Rainfall storage facility in Chunglu development area.

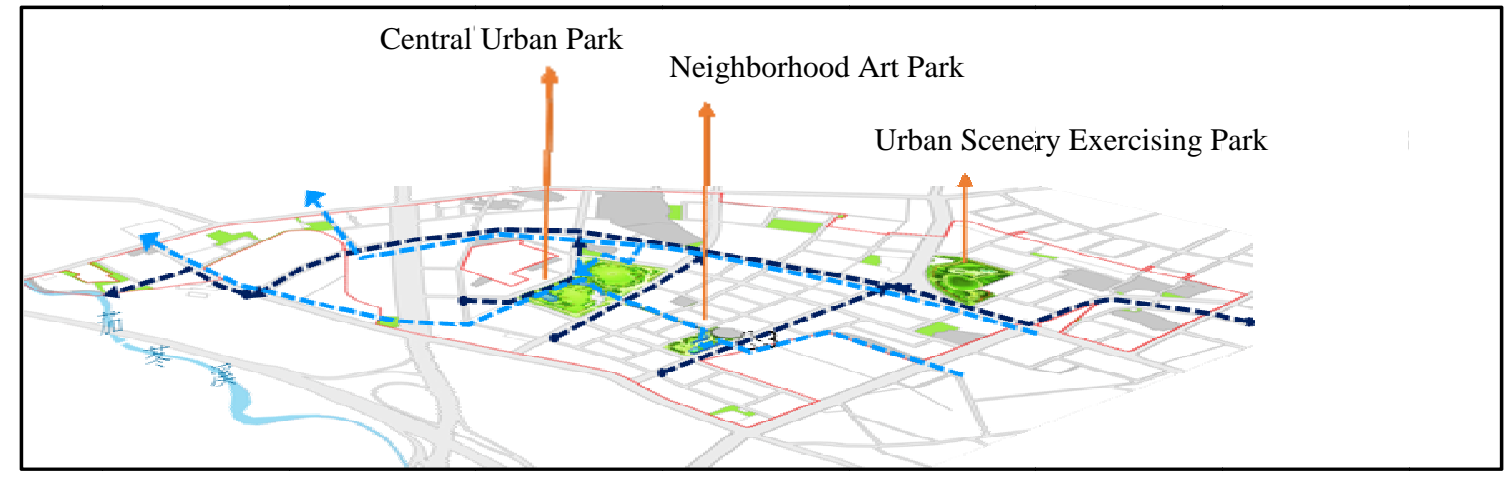

Fig. 5 Location of disaster prevention parks in Chunglu development area.

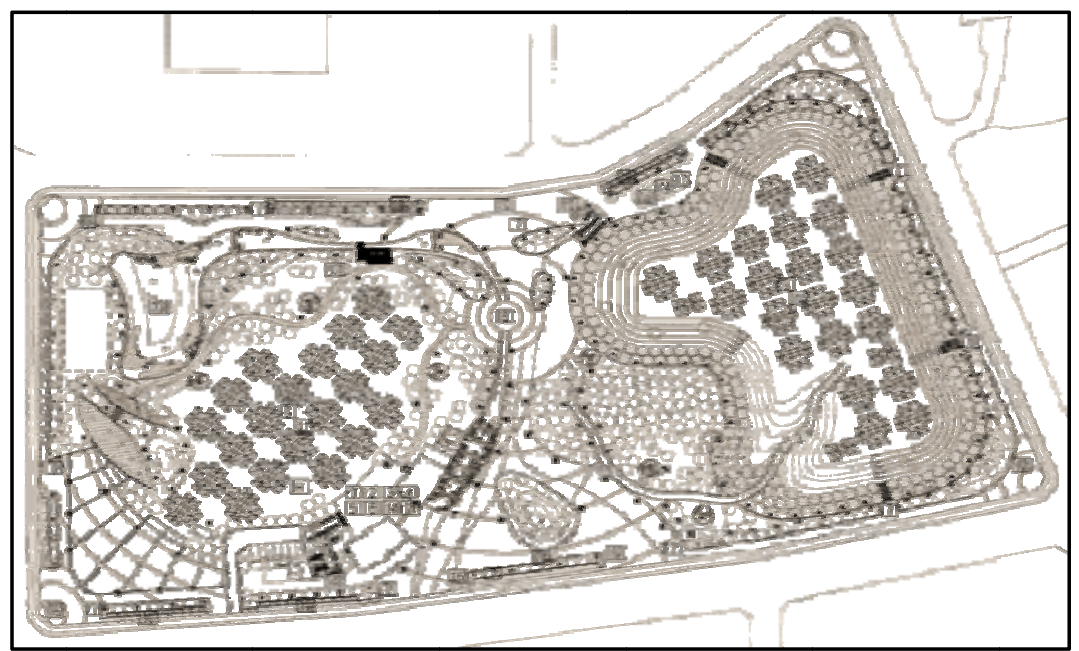

Fig. 6 Central Urban Park in Chunglu development area. 


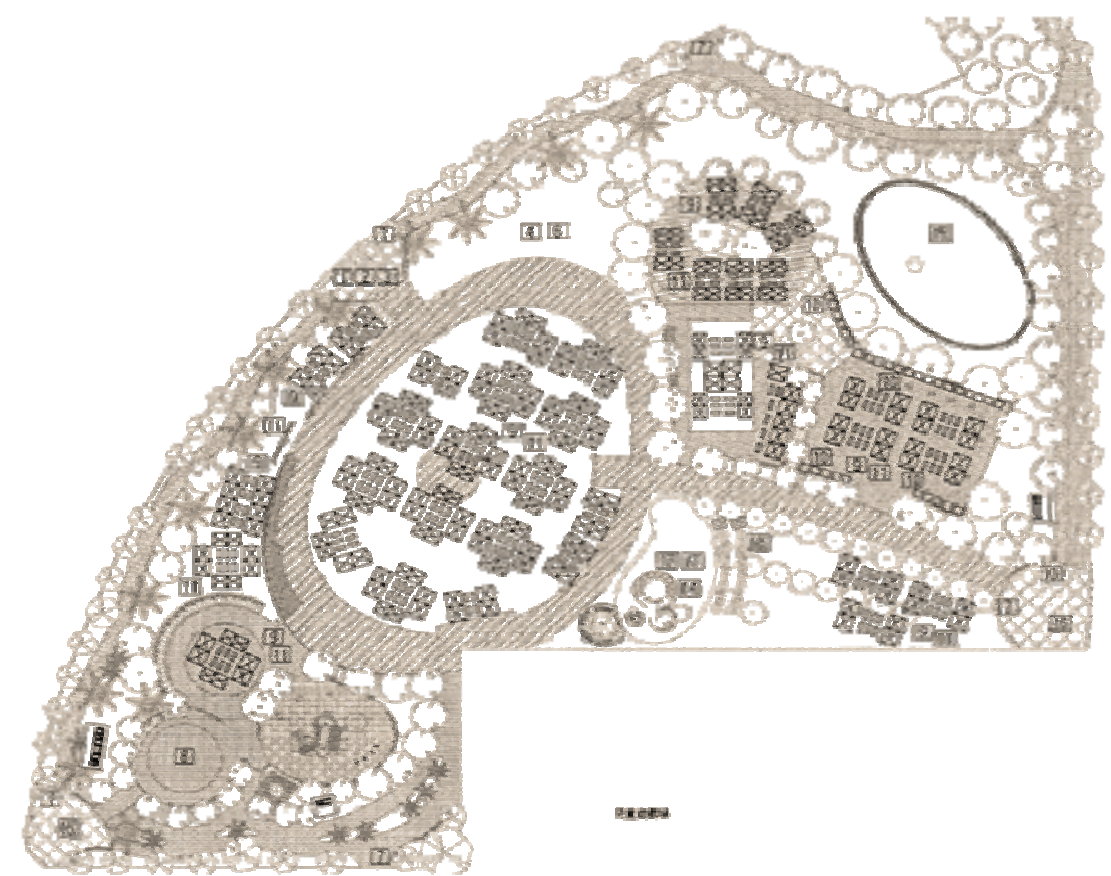

Fig. 7 Urban Scenery Exercising Park in Chunglu development area.

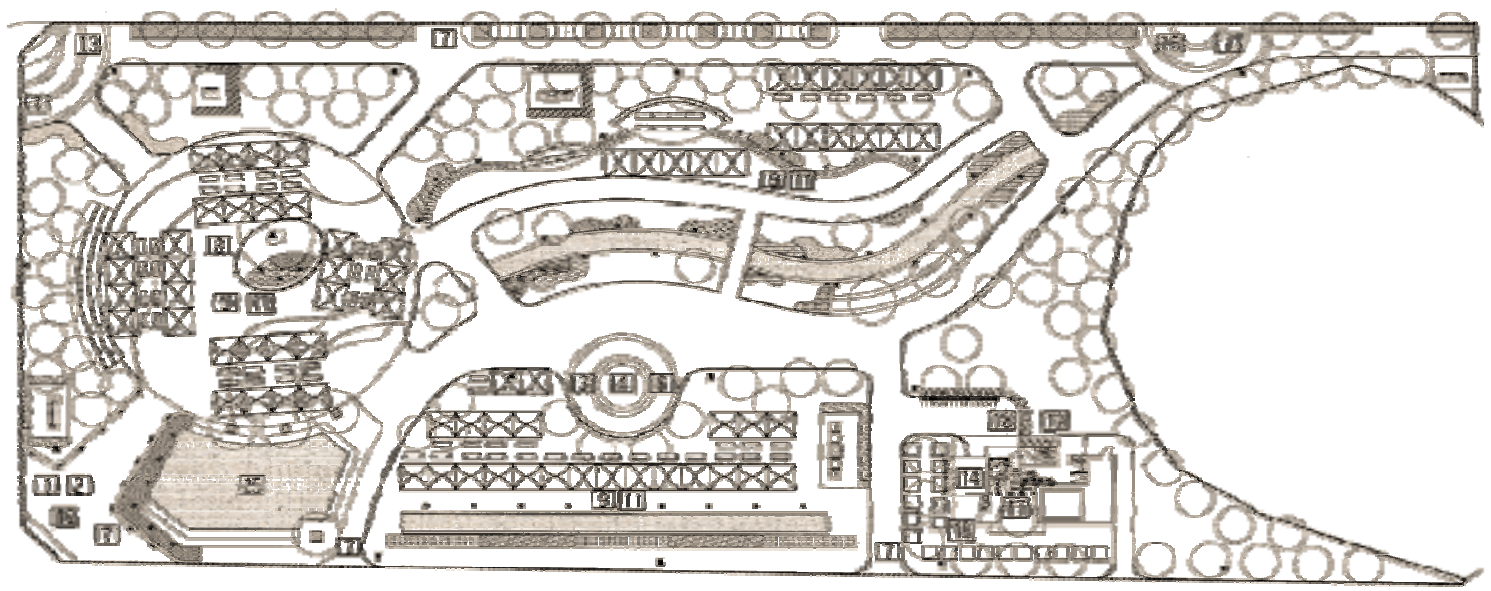

Fig. 8 Neighborhood Art Park in Chunglu development area.

on the top of disaster prevention management center could provide its own electricity usage and saves about $82.05 \mathrm{~kW}$.

Besides keeping existed 119 trees and manufacture ecologic habitat and biological diversity, the existed two irrigation channels flow through whole area with convenient ecological water level resulting in adjusting microclimate condition and decreasing the effect of urban heat island.

\subsection{Disaster Prevention Drill}

Furthermore, in order to achieve the goal of disaster prevention in the community, allow local government better understand the facility and operation of the disaster prevention park, Taoyuan City Government host a disaster prevention drill in Chunglu area on March 6, 2014. The drill was based on the real situation of the city and focused on disaster emergency response measures of evacuation and shelter function after the occurrence of earthquake. The drill not only showed the major functions of disaster prevention parks which was designed from the very beginning but to strengthen the emergency operation ability of the local government. 


\section{Conclusions}

The simulation Scenario A1B explores that river discharge will increase in wet season and decrease in dry season in Taiwan from 2020 to 2039. That is, the impaction of local climate change in Taoyuan will be increasing temperature, rainfall intensity, soil erosion, extreme rainfall events, drought and decreasing agricultural product. Hence, Taoyuan City Government made a policy decision of each urban plan having a responsibility to absorb increased runoff from its development and operation. And, green, ecology, resilience and sustainability will be the core value of urban plan.

Associated with the zone-expropriation project of Chunglu, the high-quality landscape of park is designed functions of low impact development, recreation, LOHAS (lifestyles of health and sustainability), as well as disaster prevention.

More than $40 \%$ area of public facilities includes disaster-prevention parks, detention ponds and other elementary facilities. The acquisition of private land area is very difficult even choosing type of zone expropriation. During each stage of zone expropriation, the support of landlord and Mayor Wu is very important. Hundreds of information meetings with landlord and revising project content of consultant-company would be the basis of this successful project.

\section{References}

[1] Council of Agriculture, R.O.C. 2003. Soil and Water Conservation Technical Criteria. Taiwan: Council of Agriculture.

[2] Taoyuan County Government. 2012. Integrated Planning and Elementary Design for Zone Expropriation of Taoyuan Chunglu in Taoyuan County. Final report, Taoyuan County Government.

[3] Taoyuan County Government. 2008. Integrated Review and Investigation of Rainwater Sewer Construction in Flood Prone Areas of Taoyuan County. Taiwan: Taoyuan County Government.

[4] Chen, W. P. 2004. "Design and Planning of Disaster Prevention Park in Taipei City-A Case Study in Taan Forest Park.” Master thesis, Department of Architecture, National Taipei University of Technology.

[5] Lin, S. T. 2006. "Research on Facility Design Criteria of Urban Disaster Prevention Park.” Master thesis, Department of Architecture and Urban planning, Chung Hua University.

[6] Transportation Ministry, R.O.C. 2001. Highway Drainage Design Criteria. Taiwan: Transportation Ministry. 